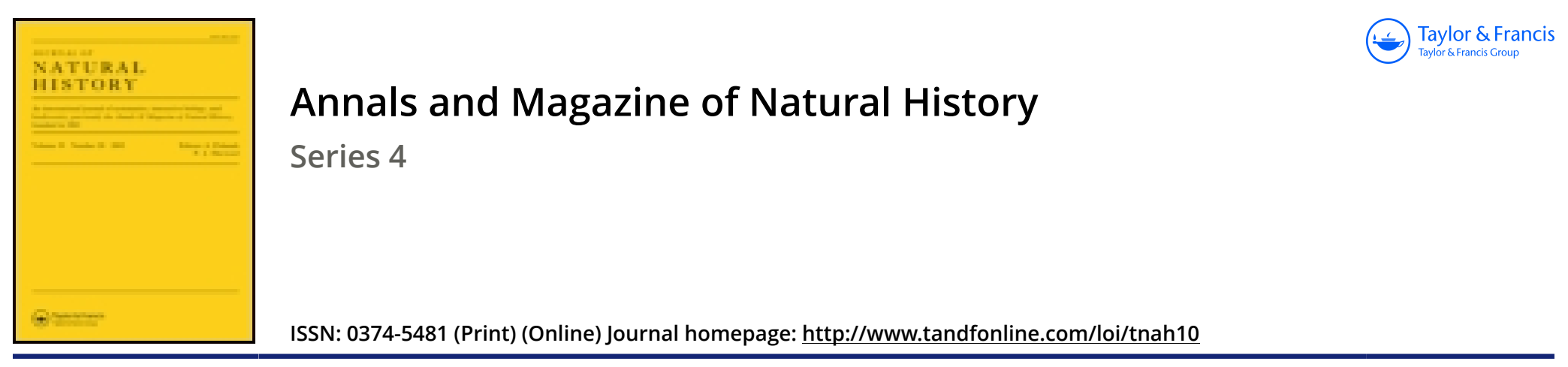

\title{
VIII.-On the structure of the skeleton of Euplectella aspergillum. (In a Letter to T. J. Moore, Curator of the Free Public Museum, Liverpool.)
}

\section{Thomas Higgin}

To cite this article: Thomas Higgin (1874) VIII._-On the structure of the skeleton of Euplectella aspergillum. (In a Letter to T. J. Moore, Curator of the Free Public Museum, Liverpool.), Annals and Magazine of Natural History, 13:73, 44-48, DOI: 10.1080/00222937408562428

To link to this article: http://dx.doi.org/10.1080/00222937408562428

曲 Published online: 22 Oct 2009.

Submit your article to this journal $\pi$

Џll Article views: 3

Q View related articles $\sqsubset$ 
It is the same with the septa of the polypary. The number 12 is first of all produced, but with this difference, that the 12 elements all begin to show themselves at the same moment; and it is only later on that their unequal growth ranges them in two groups which appear to be of different age, whereas they are only of different sizes.

The facts here brought forward appear to us to be of absolute certainty. They have been repeatedly confirmed, sometimes upon polypes taken swimming in the sea in the form of the embryonic sphere without any divisions, and brought up until the complete formation of their polypary, which was affixed to the walls of the microscopic cells in which they were kept for observation, which enabled us to follow under the microscope a single embryo, of which the origin of the parts and the formation of the framework might thus be watched-and sometimes also upon very young individuals collected on the rocks of the localities inhabited by Astroides or Balanophyllice.

VIII.-On the Structure of the Skeleton of Euplectella aspergillum. By Thomas Higgrn, Member of the Liverpool Microscopical Society. (In a Letter to T. J.Moone, Curator of the Free Public Museum, Liverpool.)

[Plate III.]

[THE specimen referred to in the following paper is one of two examples purchased of Mr. Geale in November 1866 . It is 12 inches in length measured along the outer curve, and of a very uniform diameter of 1 inch. The other specimen is somewhat longer and stouter. Both are in a more natural condition than is seen in the examples usually submitted for sale; and both are of a pale brown colour. The smaller specimen is somewhat compressed towards the top, perhaps owing to pressure while drying; and nearly half the lid-like top is torn away, leaving a jagged edge, marring the beauty of the specimen. The lower third of the sponge is rigid, the rest soft and yielding throughout, the rigidity extending somewhat higher upon the inner than on the outer side of the curve.

It is, as Mr. Higgin supposes, the specimen referred to by Prof. Wyville Thomson in his "Letters from H.M.S. Challenger," published in 'Good Words' for July 1873, p. 510. On passing through Liverpool to Belfast in December 1868, he paid a hurried visit to the Museum, saw both examples, and I gave him a fragment from the smaller one for use under the microscope. It is remarkable that all the specimens 
of Euplectella dredged by him off Cape St. Vincent should be uniformly in the condition indicated by the soft part of our sponge. His remarks are as follows :-

"Several samples of Euplectella, very closely allied to the Philippine species, if not identical with it, came up in the trawl off Cape St. Vincent, and gave us an opportunity for the first time of seeing this sponge alive. Dr. J. E. Gray writes to the 'Annals and Magazine of Natural History' that specimens have been received of Euplectella aspergillum in spirit, and that in these the glassy framework is entirely masked by a soft, brown, corky coating of sarcode. Our fresh specimens entirely bear out Dr. Gray's description. It would be difficult to imagine that the thick, somewhat clumsy brown tube, perforated with irregular openings, contained any arrangement of support so delicate and symmetrical.

"Although the forms of all the spicules, down to the most minute and complicated, are identical, the wall of the tube in the European specimens of Euplectella is not coherent as in most of the Philippine examples. The original spicules of the skeleton remain separate from one another, and do not become soldered together. One would think that this would be at all events a perfect specific distinction; but one or two of the specimens of Euplectella aspergillum, particularly one in the Museum at Liverpool, are in this condition; and I am not yet prepared to say whether all may not be thus soft at a particular stage of growth."

Mr. Higgin is well known in Liverpool for his great success in micro-photography. He has for some months been earnestly engaged in the study of sponges, and has kindly given this museum the benefit of his assistance in working up the tolerably numerous specimens already got together. It is a great pleasure and satisfaction to announce a new and zealous worker in a department of zoology so little cultivated, and in which there is so much work to be done.-T. J. Moore.]

\section{My dear Mr. Moore,}

Huyton, November 15, 1873.

The Euplectella which you have placed in my hands for examination is a very interesting and valuable specimen; for it reveals the composition of the network of these beautiful sponges, which I believe has not hitherto been exactly known.

Your sponge is rigid only to the extent of a few inches from the base, and is flexible throughout the rest of the tube. The cause of rigidity in Euplectella is the enclosure within a silicious coating of the spicules which form the fibres, which coating, for convenience' sake, has been called vitreous. This 
vitreous coating being of the same nature as the spicules themselves, their outlines become lost to sight in it ; it is impossible to distinguish them and trace their form and shape. Most, if not all, of the specimens which are brought to this country from the Philippine Islands are of this rigid character; and consequently the structure of the network remains undescribed. In your specimen, however, we have part of the network vitrified and part of it unvitrified; and in the unvitrified portion all the spicules are easily traceable and distinguishable, lying in the position they are destined to occupy in the rigid skeleton, ready for the silicious coating to be poured over them.

This, I understand, is the sponge to which Prof. Wyville Thomson alludes in his letter from the 'Challenger,' which appeared in the number of 'Good Words' for July last, where he speaks of the examples of Euplectella which were brought up in the trawl off Cape St. Vincent, the spicules of which were not soldered together, but were in the same condition throughout as those of a specimen of Euplectella in the Liverpool Museum. I learn, too, from Mr. H. J. Carter, of Budleigh-Salterton, that "Dr. Semper, of Würtzburg, had seen specimens of Euplectella aspergillum without any vitrified fibre, which he had viewed as young specimens in which the whole would have become vitrified if they had remained long enough in their natural place of growth-that, in fact, the flexible or unvitrified is the primary state of this species."

The groundwork of the square meshes is an arrangement of very large four-rayed spicules, the arms of which lie longitudinally and transversely; and so large are these spicules that they do not require to be measured under the microscope by the 100 th or 1000 th of an inch, but may be measured with an ordinary pocket-rule; each transverse arm extends over three to four of the square areas, so that from the tip of the one to the right to the tip of the one to the left is three quarters of an inch to an inch, and the longitudinal arms are still longer. I may here remark that these are genuine four-rayed spicules, and that at the central spot there is no appearance of suppressed arms. As the square areas only measure about one eighth of an inch each, it will be evident that the long arms of these spicules must extend towards each other, meet, and lie alongside one another, the tapering end of one extending up towards the thickest part of another. Along these interlocking arms are placed long, straight, and very slender spicules, which are spined from the extremities for a considerable distance along the shaft (Pl. III. fig. 7).

The diagonal lines and all the fine filaments are the long arms of four-rayed and six-rayed spicules, only three of 
Ann \& Mag Nat Hist S.4 Vol 13. Pl III

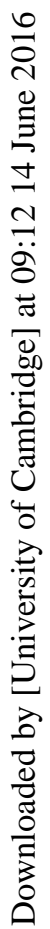

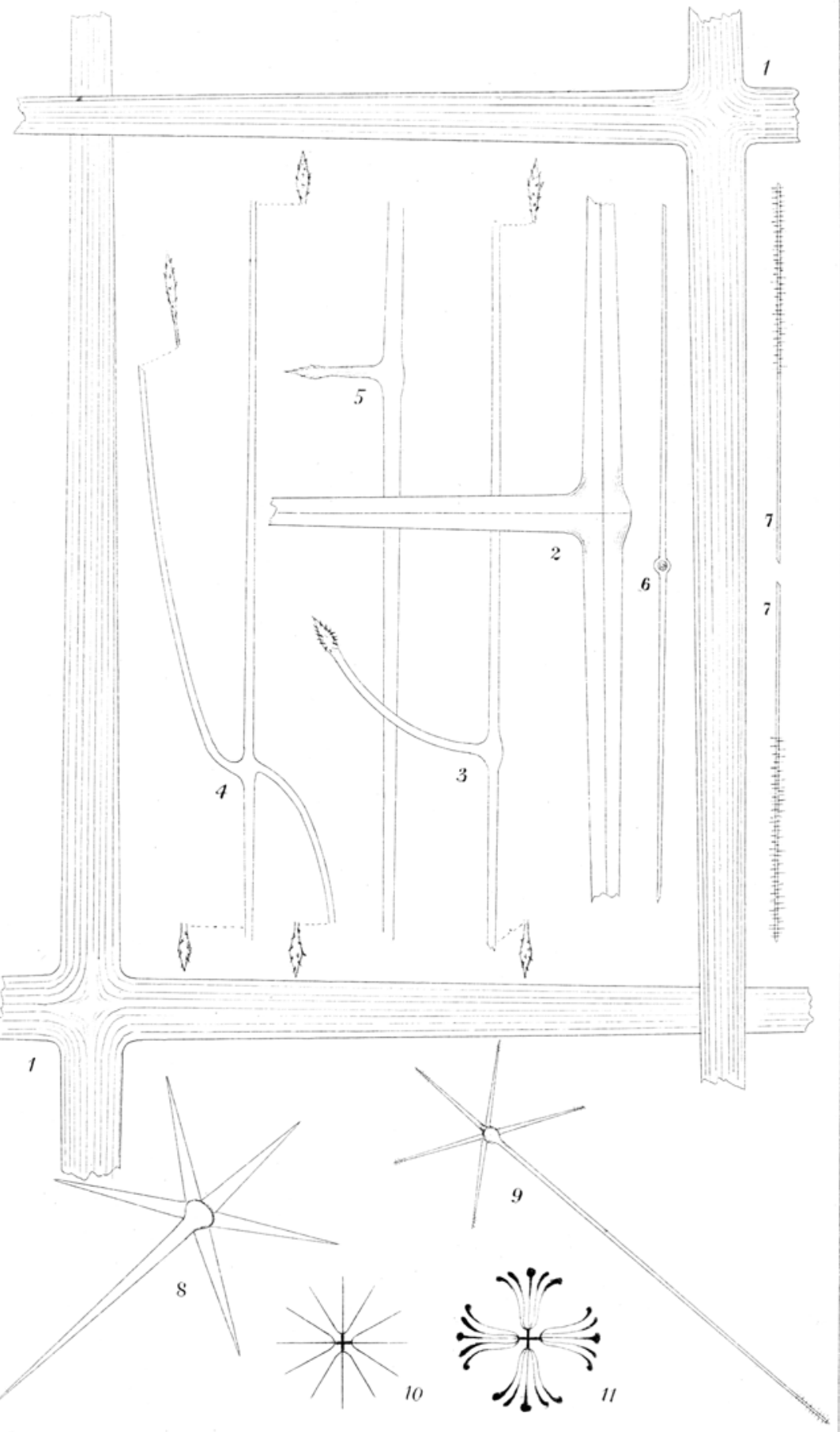


which, however, are usually produced, the other arms being more or less suppressed or abortive; the tips of the arms terminate in a kind of spear-head form which is spined; these arms are all extremely long, and some exceedingly slender, and they are twisted and bent in a variety of ways to suit the pattern of the network.

The open network of the mouth of the tube is composed of similar spicules interwoven together.

The exterior "ridges or frills" are also built up of spicules of the same form, the arrangement being that two or more long arms or rays lie along the network of the skeleton, whilst another arm, which is a short or dwarf one, stands up perpendicularly to the surface. These short upright arms are so placed as to form the lines of the ridges; and amongst them are interlaced the long slender rays of other spicules, in some of which all the transverse arms are suppressed. These ridges therefore contain the principle availed of in mechanical engineering in the $\perp$ iron girder.

Interspersed throughout the whole of the network are numerous smaller sexradiate spicules, chiefly of slender form; but there are some with short stout arms which are quite smooth; the arms of the slender ones are all spined at the ends, and one of the longitudinal arms is usually produced to a great length.

The flesh-spicules are the "rosettes" of the two kinds described and figured by Mr. H. J. Carter in the November Number of 'Ann. and Mag. of Nat. Hist.' plate xiii. figs. 4 and $11,1873$.

Exteriorly there are bundles of long straight spicules or rods running along the longitudinal lines of the skeleton for some distance from the base, some of which are smooth, and others barbed.

It is a matter of great satisfaction to have met with a specimen of this species of sponge in which the vitrification is in progress : here it is actually so. In the lower part of the network to which the vitreous cement has been applied, it has been deposited in sufficient quantity to render the skeleton rigid, but not in such quantity or so completely as in the usual rigid examples. The examination of a portion, after boiling in nitric acid and subjecting to considerable heat, shows that the silicious coating has been deposited in layers, just as in the case of the spicules, the only difference, apparently, being that as cement it is amorphous, whilst in the spicules it assumes definite forms. The spicules of this species are, as Mr. Carter remarks, imbedded in vitreous material, much in the same manner as in the horny-fibred sponges the spicules are imbedded in horny material. In the Chalinæ, how- 
ever, and sponges of that character, the enclosing material is added as the spicules are projected and placed in position, they being of a form not able to hold together without extraneous aid. But in the beantiful Euplectella we have what does not occur in sponges generally (if, indeed, it occurs at all in any other species) - that a structure is built up after a particular design which, when finished, is not added to, and which with slight variations obtains in all specimens: the wonderful basketwork made up by the interlacing or interweaving of the unusually long fine arms or rays of the various spicules is capable of holding together of itself by reason of its form; and the cementing material cannot advantageously be added until this is all complete; but when the whole structure has been finished according to the pattern which is constant in the species, the vitreous coating may be applied and the entire skeleton rendered rigid. Perhaps this silicious cement is not added in some localities; but in the examples from the Philippine Islands the unvitrified state appears to be, as Dr. Semper suggests, the primary state.

$$
\begin{aligned}
& \text { I am, dear Mr. Moore, } \\
& \text { Yours very truly, } \\
& \text { T. HIGGIN. }
\end{aligned}
$$

\section{EXPLANATION OF PLATE III.}

Fig. 1. 1. Large spicules forming ground-plan of the "squarish areas" or meshes, showing the position they occupy with respect to each other. Diameter of shaft at thickest point $\frac{1}{200}$ inch ; length of each transverse arm about $\frac{3}{B}$ inch; length of each longitudinal arm about $\frac{3}{4}$ inch.

Fig. 2. One of the spicules of the diagonal lines, showing three arms only produced.

Fig. 3. A spicule, showing a suppressed arm and an abortive arm.

Fig. 4. A spicule, showing one of the various ways in which the arms are bent to suit the pattern.

Fig. 5. One of the spicules of the ridges or frills.

Fig. 6. A spicule, with all the transverse arms suppressed.

Fig. 7. 7. One of the tine straight spicules which lie along the arms of the large spicules, fig.1.1.

Fig. 8. One of the smooth stout sexradiate spicules interspersed amongst the network.

Fig. 9. One of the attenuate sexradiate spicules, spined at the ends of the arms, found interspersed amongst the network and sarcode.

Figs. 10 \& 11 . "Flesh-spicules," "rosettes."

The spicules 8 and 9 are very frequently found with the short longitudinal arm suppressed.

The figures represent the proportionate sizes of the spicules, with the exception of the smaller sexradiate forms, which are on a larger scale. 